\title{
Interdisciplinarity as Inspiration: A Case Study
}

\section{Mr. Skot Wiedmann, University of Illinois, Urbana-Champaign}

Skot Wiedmann works in the Department of Electrical and Computer Engineering at the University of Illinois at Urbana Champaign. His undergraduate degree is in Digital Interactivity from the University of Wisconsin. His masters work in fine art led to a decidedly interdisciplinary approach to making. 


\title{
Interdisciplinarity as Inspiration: A Case Study
}

\author{
Skot Wiedmann \\ University of Illinois at Urbana Champaign
}

\section{Introduction}

The potential for interdisciplinary approaches to education in efforts to inspire learners has been shown to be fruitful in K12 and college level curricula ${ }^{1-7}$. A movement combining Art \& Design with STEM has promoted the benefits of STEAM ${ }^{8}$. In addition to the improved performance of students who are engaged in this type of curriculum, there are opportunities to develop projects that embody the interdisciplinarity of these practices ${ }^{9}$. Workshops held in 2014 and 2015 successfully promoted engagement and collaboration, and inspired learners who attended to build their own touch synthesizer. By emphasizing the aesthetics and musicality of the end result, the promotion of the event aimed to broaden K12, community and non-engineering student participation by attracting creative people to learn technical skills alongside the electrical engineering students who typically attend soldering workshops. This series of soldering workshops brought together engineering, music, and design ideas to inspire and engage a wide range of people. The synthesizer that participants built was designed to transcend a skill building activity through an interdisciplinary approach to making. Large attendance and continuing demand for touch synthesizer workshop sessions illustrate how a new approach to engineering education focusing on an interdisciplinary perspective can create a more holistic idea of the purpose of students' education and inspire learners to passionately engage with their curriculum $^{10}$.

\section{Pedagogical Goals}

The touch synthesizer workshop began as a means to fill a gap in the existing University Electrical and Computer Education and to enrich student experiences beyond the classroom by teaching surface mount soldering techniques. By introducing electronic assembly, analysis, and rework, in the context of making sound and music, we aimed to inspire students to connect their interests, hobbies, and passions with their chosen field of study, even if they are traditionally isolated practices ${ }^{11}$. We hoped to draw a diverse audience that reflected the varying perspectives on these practices, and encouraged high school outreach and pre-college involvement. We wanted participants to gain exposure to manufacturing processes that are common for most 
consumer devices, but are not often used in soldering workshops. Finally we wanted to inspire students to discover and increase their passion for engineering, music, and design by offering an interdisciplinary and rich experience.

\section{Workshop}

Participants arrived and were given the printed circuit board (PCB) which was then stenciled with solder paste. This selectively deposits solder paste onto the pads where the components are attached in a process that is similar to silk screen printing a t-shirt. Participants took a seat at a table with the kit they received containing the PCB, small tweezers, and a parts checklist. Volunteers distributed the first component on the list, indicating its value and location designator both on the checklist and PCB. They guided the participants through placement with the tweezers. One by one parts were distributed, and the process continued until the PCB was fully populated. This allowed participants to work quickly without spending time sorting out the next part in a kit, and provided an educational strategy well suited to a novice learning style. The layout of the parts had clear designators with individual outlines showing where each part should be placed, so people had no trouble installing the components, even though there were over 50 on the PCB. In about an hour all the parts were placed and participants were directed to one of the hot air stations at the front of the room to apply heat that would melt the solder into place making the connections between the components and the PCB. Soldering this way takes under 5 minutes for each PCB. We had 8 hot air stations, although it could be done with fewer stations depending on the group size. The organizers noted the enthusiasm of participants as they heard the first sounds coming from their creation. Small mistakes could easily be identified. One silent key, for example, could be tracked down to the voice for that note, which is labeled and isolated from the other voices. Small soldering fixes were completed with a standard soldering iron in an area where volunteers were helping to diagnose and fix problems. This basic introduction to debugging gave participants confidence to test and explore the circuit even if this was their first exposure to electronics. The evening concluded with some demonstrations and exploration as the last few people got everything working. The whole process was completed in around 2 hours with minimal facilities and setup even for large groups. 


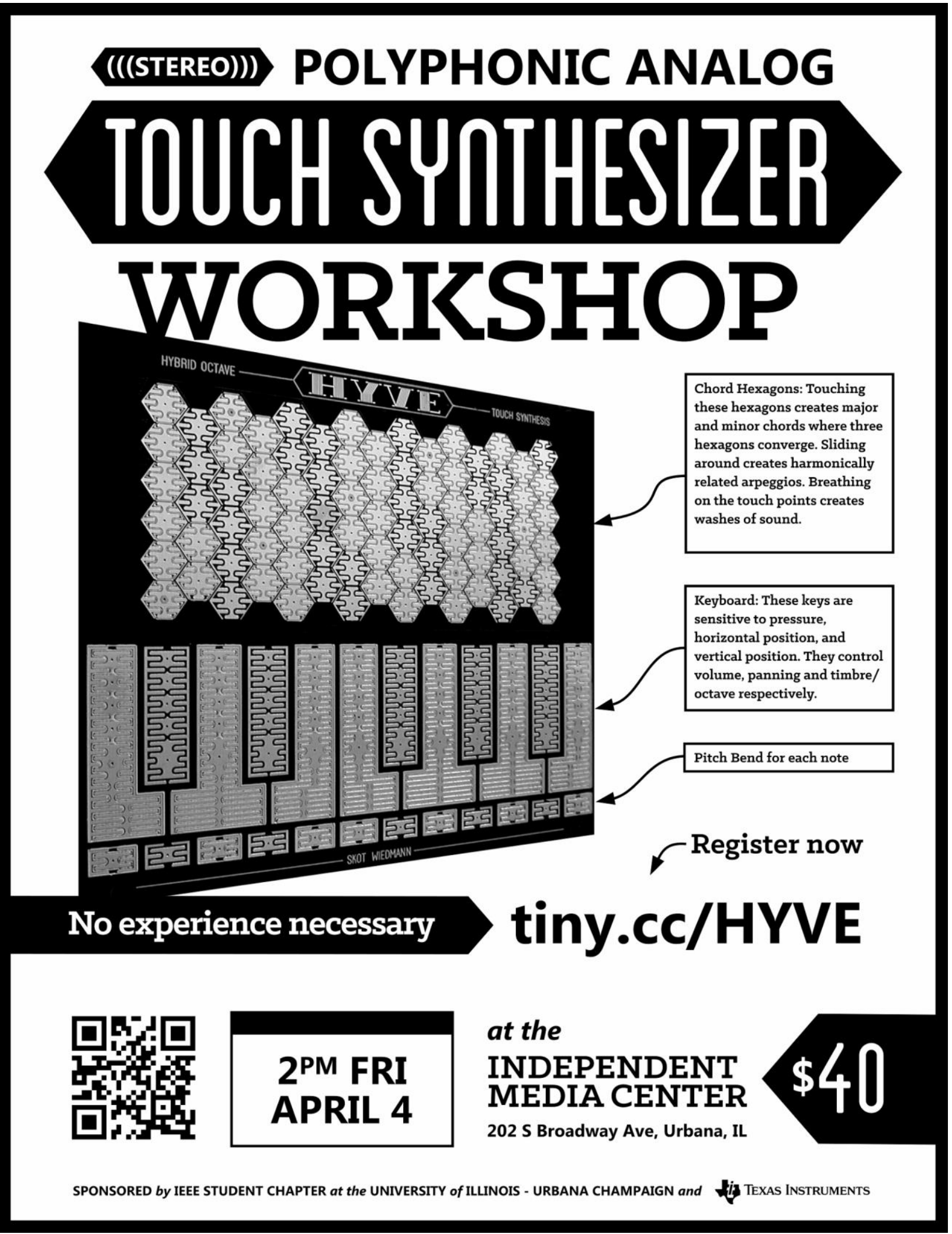

Fig. 1 Workshop promotional poster 


\section{Promotion}

By contextualizing unknown material in a known framework, learners can gain access and approach the material with confidence. Furthermore, the framework has the potential to be an inspiration when it connects with a person's wider experiences and interests. In particular, music and sound making were given more weight than skill building. Instead of offering a how-tosolder session, the promotional materials invited participants to build their own touch synthesizer (fig.1). The language avoided an exclusionary voice where it would be easy to conclude that it is intended for one field of study only. Many participants did not identify as musicians, but were compelled by the idea of making sounds by touching a circuit they created. This combination of motivators resulted in a large turnout of excited participants. Students in electrical engineering often attend workshops to learn a useful skill and participate in a social activity. By coupling this idea with an interdisciplinary perspective, while leveraging the desire to create an innovative musical instrument, the experience transcended a skill building activity to become a catalyst for further curiosity and investigation. Participants could learn about the manufacturing process, stenciling solder paste and placing parts before hot air reflow, which is how most consumer electronics are made.

\section{Demographics}

When situating education in an interdisciplinary context, learners are encouraged to bring their history and prior knowledge to bear on the new material, and are able to think creatively in making connections that are otherwise unlikely. Diversity increases as students who would otherwise feel like outsiders gain access and validation. Peer learning was key in facilitating this program, and offered participants a forum to meet people from different fields with a shared interest. The promotional materials stated "no experience necessary" and the event was advertised around campus and in the community, as well as at a large K12 outreach event where hundreds of visitors were invited to try it themselves. The demographic of the participants was skewed toward electrical engineering students that came from the department where the events were held. However, there was significant participation from high school students, faculty, and community members. This mix created a learning environment that was collaborative and collective. 

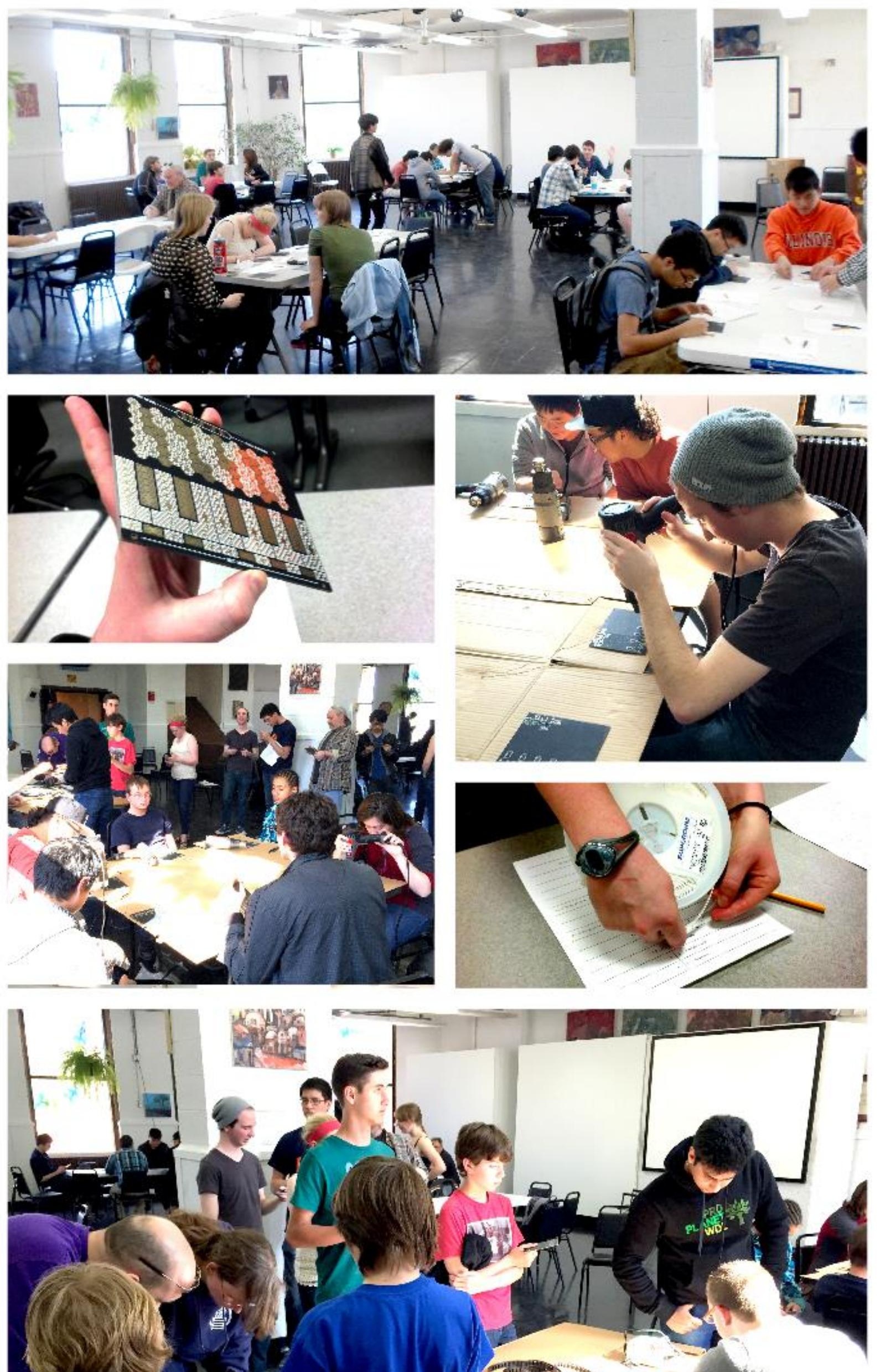
Fig. 2 Workshops

\section{Design}

The design of the Hyve Touch Synthesizer plays on the familiarity of touch screen interfaces but challenges the perception that these devices are closed and unmodifiable by the average person, instead offering an empowering experience to participants. The circuit board is laid open with all the components on one side, leveraging themes from the hacker and maker movements where full access to the devices we use is held in high esteem. The other side forms the user interface where touching affects the circuit and allows one's skin to redirect the flow of electricity. While many hackers celebrate the raw nature of their practice, this instrument is arranged in an aestheticized way. The geometric layout and gold plated contacts invite approaching it as an instrument with complex and sophisticated possibilities. This only increased the excitement and pride that participants experienced when they saw what they made themselves. 


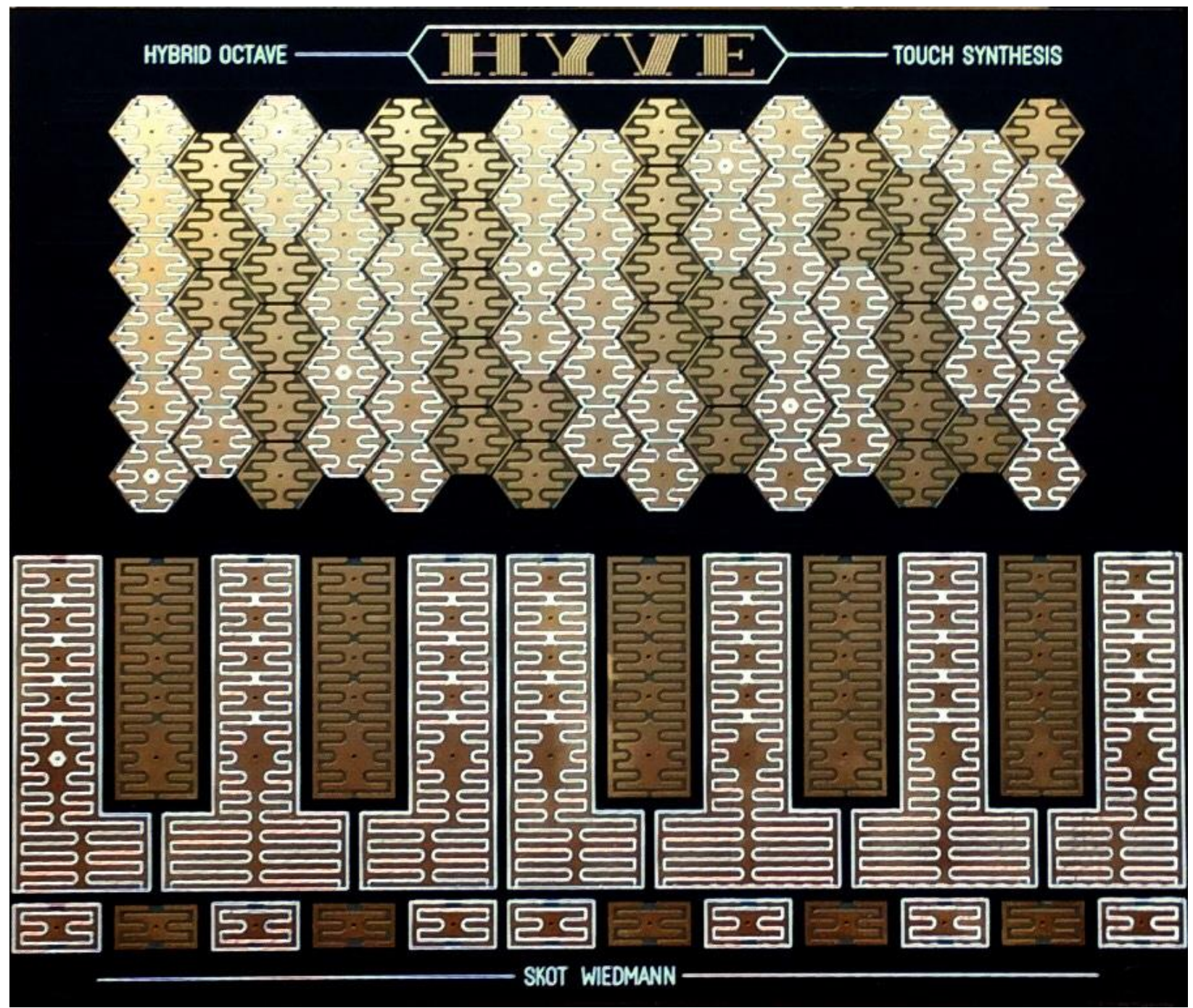

Fig. 3 The user interface of the Hyve Touch Synthesizer

\section{Instrument}

The instrument that the participants built is called the Hyve Touch Synthesizer. It is a 2-layer printed circuit board measuring 6 by 5 inches with a touch interface on the front (fig. 3) and circuitry on the back (fig. 4). The bottom half of the user interface mimics the layout of one octave of a piano keyboard. Each key senses pressure, horizontal position, and vertical position independently. There are also pads along the bottom for pitch bending of each note. The top half has an array of hexagons which also sense pressure and position. Adjacent hexagons have harmonically related tones to allow exploration of harmonies and chords by playing a group of hexagons with one finger in an arrangement called Tonnetz (Tone Network) first introduced by Leonhard Euler in 1739. ${ }^{12}$ This allows an opportunity to introduce some fundamentals of music 
theory. The voice architecture is fully analog, with 12 oscillators, one for each note. All octaves of each note are derived from these oscillators, which are then controlled by the touch interface through a pair of filters. Pressure on each key controls the loudness of each note independently, as it opens the filters. Each note can be located in the stereo field - panning right and left - by horizontal movements on the touch surface within each key area. Vertical movements affect the timbre and octave of each note. Along the bottom, a series of pressure sensitive pitch bending points is associated with each key. The resulting sound is available on the headphone output jack. The power input accepts 6-15VDC on a common barrel connector, and has reverse polarity protection and local regulation on board to create the $5 \mathrm{~V}$ system power. A demonstration of the Hyve Touch Synthesizer in use can be seen at: https://youtu.be/74u6tWNJ1vQ

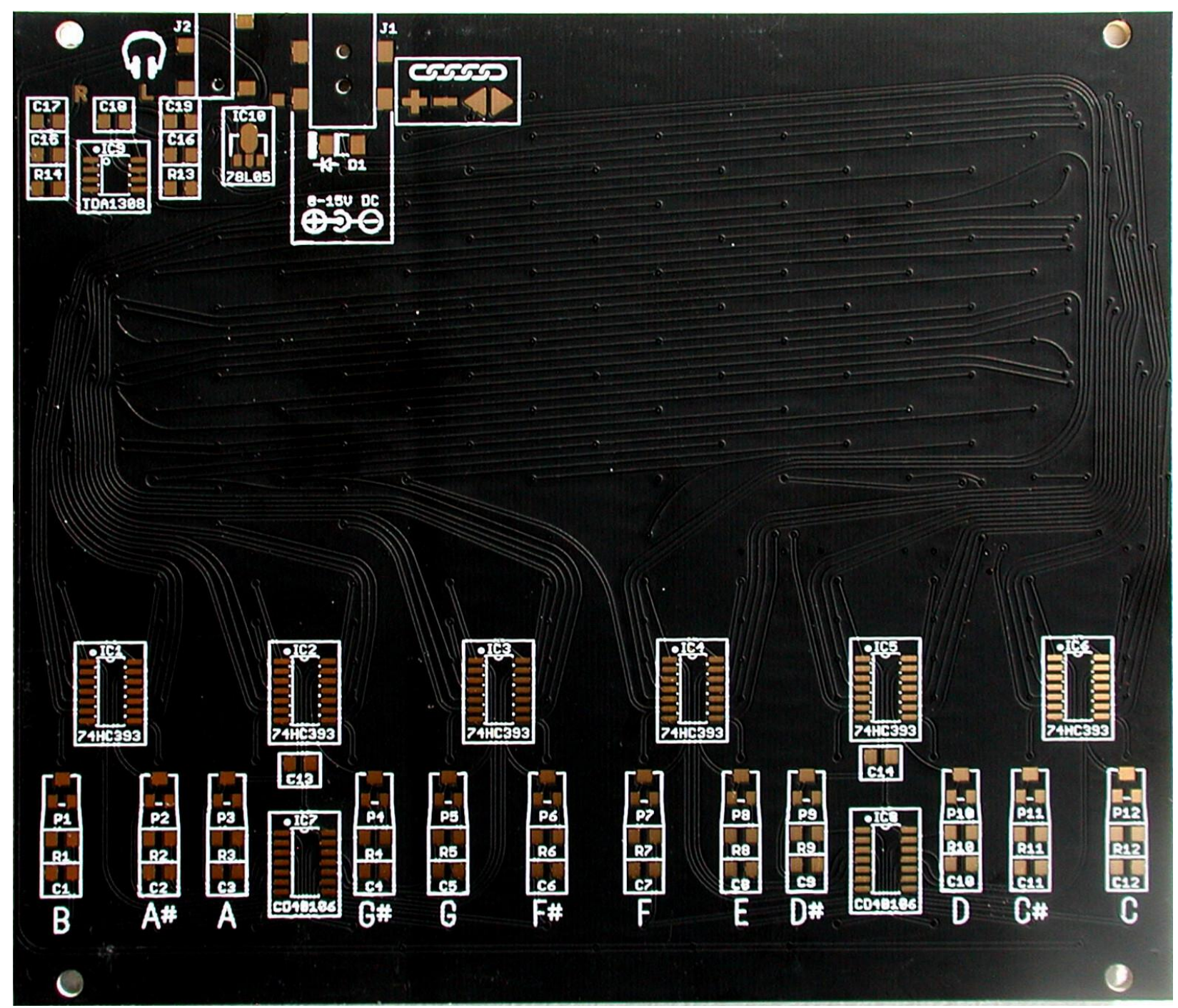

Fig. 4 The component side of the Hyve Touch Synthesizer 


\section{Conclusion}

This workshop attracted nearly double the participants compared to workshops held in past semesters. Previously, an Arduino workshop attracted 50 participants, while this workshop was attended by over 90 people. The pre-registration numbers exceeded the venue and the event was expanded to 2 sessions. In the second session there were participants who heard about it through participants from the first session who showed them what they had made. Similarly, the following semester the demand was high enough to offer the same workshop again, and many people reported hearing about it from those who attended previously. There were a few participants who attended multiple times and some that wanted to build multiple units at one workshop. The events drew a diverse range of backgrounds beyond electrical engineering students who were the primary audience. Students and faculty from Music, Business, and Art were present. The youngest participant was 8 years old, and a few retired people came. All participants left with a working circuit even though some of the electronic components were not well marked and could easily be installed backwards. A few of the participants needed multiple rounds of debugging and rework, but it was noted that they were persistent and motivated just as much by aesthetic experience as technical knowledge. The workshop series provided a platform for outreach and was covered in some media outlets: https://www.ece.illinois.edu/newsroom/article/8012 In future sessions, surveys could better gauge the effectiveness of this curriculum. Evaluating this workshop in terms of fluency, interest, and engagement with STEAM topics could provide developments and insights leading to other possible workshops and curricula. Deploying this idea within a classroom or coursework could offer perspectives that would be fruitful to middle and high school classes, as well as supporting engineering teaching at the college level. 
[1] Foster, G. N. (1998, June), Using Sound And Music In Technology Paper presented at 1998 Annual Conference, Seattle, Washington. https://peer.asee.org/7513

[2] Head, L. M. (2011, June), Signals, Systems, and Music: General Education for an Integrated Curriculum Paper presented at 2011 Annual Conference \& Exposition, Vancouver, BC. https://peer.asee.org/18807

[3] Shepard, T., \& Carlin, B. W. (2014, June), A First-Year Soldering and Analog Music to Light Modulator Electronics Lab Project Paper presented at 2014 ASEE Annual Conference, Indianapolis, Indiana. https://peer.asee.org/19940

[4] Rhudy, M., \& Rossmann, T. (2015, June), Musical Analogies as a Teaching Tool for Engineering Concepts Paper presented at 2015 ASEE Annual Conference and Exposition, Seattle, Washington. 10.18260/p.24517

[5] Park, W. (1998, June), Electronic Music Techniques Used To Enhance Introductory Circuit Analysis Paper presented at 1998 Annual Conference, Seattle, Washington.

https://peer.asee.org/7076

[6] Stace, S., \& Medoff, H., \& Margle, J. (2003, June), Incorporating Musical Instrument Design Into A Freshmen Engineering Course Paper presented at 2003 Annual Conference, Nashville, Tennessee. https://peer.asee.org/12535

[7] Rogers, C., \& McDonald, J., \& Nocera, T., \& Cyr, M. (1998, June), The Design And Performance Of Musical Instruments Paper presented at 1998 Annual Conference, Seattle, Washington. https://peer.asee.org/7015 
[8] Robinson, C., \& Baxter, S. C. (2013, June), Turning STEM into STEAM Paper presented at 2013 ASEE Annual Conference, Atlanta, Georgia. https://peer.asee.org/22656

[9] Gregorio, J., \& Morton, B. G., \& Kim, Y., \& Ward, J. S. (2013, June), Music Technology as a Vehicle to STEM/STEAM for High School Students Paper presented at 2013 ASEE Annual Conference, Atlanta, Georgia. https://peer.asee.org/22306

[10] Cox, I., \& Cox, M. F. (2013, June), Integrating STEM and the Arts: A Call for Partnerships across Disciplines Paper presented at 2013 ASEE Annual Conference, Atlanta, Georgia. https://peer.asee.org/19796

[11] Batula, A. M., \& Morton, B. G., \& Migneco, R., \& Prockup, M., \& Schmidt, E. M., \& Grunberg, D. K., \& Kim, Y., \& Fontecchio, A. K. (2012, June), Music Technology as an Introduction to STEM Paper presented at 2012 ASEE Annual Conference, San Antonio, Texas. https://peer.asee.org/21719

[12] Euler, Leonhard (1739). Tentamen novae theoriae musicae ex certissismis harmoniae principiis dilucide expositae (in Latin). Saint Petersburg Academy. p. 147. 